\title{
La red europea de iniciativas de integración económica como elemento de intercambio de experiencias en el seno de proyectos europeos transnacionales
}

ObSERVATORIo Local DE EMPLEO

UNIVERSIDAD DE HUELVA*

\section{Introducción}

En un contexto, dada la proximidad de la fecha límite, en el que la prioridad de los gobiernos de los países de la Unión Europea se centra en el cumplimiento de los criterios de convergencia nominal establecidos en Maastricht, se hace especialmente relevante hacer hincapié en la convergencia real entre las economías de dichos países.

Uno de los principales argumentos de esta convergencia real es, por supuesto, el eje de cuestiones relativas al empleo, sobre el que el gobierno de nuestra nación es consciente que ha de hacer un esfuerzo adicional si se tiene en cuenta nuestro diferencial en la tasa de desempleo con respecto a la media de los países de la Unión.

Sin embargo, pese a las diferencias en la magnitud del problema, existe una problemática cualitativamente común a todos los países miembros, a saber: el hecho de que un número cada vez mayor de ciudadanos, generalmente pertenecientes a los grupos de población socioeconómicamente más desfavorecidos, queden excluidos del mercado laboral. Es bien sabido, que esta exclusión de los mecanismos de acceso al mercado laboral, lleva, en gran número de casos, aparejada una situación de exclusión social, de la que los grupos afectados difícilmente pueden salir si no es con ayuda de la intervención pública.

* El Observatorio Local de Empleo está compuesto por las Profesoras M. J. Asensio Coto, Maria de la O Barroso, Manuela de Paz Báñez, Blanca Miedes Ugarte y Dolores Redondo Toronjo. 
En la actualidad son diversas las iniciativas comunitarias dirigidas a fomentar este tipo de actuaciones de lucha contra la exclusión, sobre todo desde la actuación en el ámbito local, que se revela como la más adecuada para articular, especialmente a través del empleo, el tejido social y la reestructuración del espacio productivo de la zonas de actuación específicas. Como consecuencia de ello son muy numerosos también los programas y proyectos que se desarrollan en nuestra comunidad en este sentido.

En este panorama de proliferación en Europa de actuaciones con un objetivo común: la creación de condiciones que permitan el acceso al empleo, se hace necesario, a la vez que conveniente, establecer un marco de investigación y reflexión también común que permita aunar los esfuerzos en este sentido mediante el intercambio de experiencias relativas a los diseños de programas, instrumentos y resultados obtenidos en las diferentes iniciativas puestas en marcha. Esta transferencia de informaciones y conocimientos posibilita en gran medida aprovechar las experiencias de otros en beneficio propio, a la vez que permite contribuir como parte activa a la redefinición o a la creación de nuevos ejes de actuación por parte de la Unión Europea.

\section{Descripción de la Red}

El diseño de este marco común de intercambio es uno de los principales objetivos de la Red Europea de Iniciativas de Integración Económica (REIIE), creada en 1992, a partir de la experiencia de técnicos y jefes de proyecto de las acciones modelo e innovadoras enmarcadas en el Tercer Programa Europeo de Lucha contra la Pobreza (Pobreza III). Este grupo de profesionales comprobaron por su propia experiencia, lo fructífero de la transferencia de conocimientos durante el desarrollo de sus respectivos proyectos.

Actualmente en la Red Europea de Iniciativas de Integración Económica (REIIE) participan dieciséis estructuras cuya principal característica es su implicación en proyectos locales que realizan acciones de integración económica. Dichas estructuras proceden de distintos países miembros de la Unión Europea (Francia, Irlanda, Alemania, Bélgica, Portugal y España). La red es así un medio de formalizar estas acciones, generalmente alternativas y experimentales, y de proponer instrumentos de transferencia eficaces, útiles para la elaboración de políticas de lucha contra la exclusión.

Las dieciséis estructuras que integran la red se estructuran en tres proyectos transnacionales, que trabajan con diferentes ejes temáticos cada uno de ellos, ligados por ejes transversales de reflexión:

* Proyecto "Catalyse": conjunto de proyectos europeos que trabajan en la observación de itinerarios de inserción sociolaboral. 
* Proyecto "Insieme": conjunto de proyectos europeos que trabajan en acciones donde la coordinación entre los distintos actores socioeconómicos en un contexto de desarrollo local es fundamental.

* Proyecto "Domino": conjunto de proyectos que trabajan en acciones de inserción por lo económico en el marco de dispositivos de desarrollo local.

Desde la constitución de la red (abril de 1992) hasta 1996, los participantes de ésta han organizado nueve seminarios cuya temática general se relaciona a continuación:

* Creación de la REIIE.

* Empleabilidad de las personas con dificultades.

* Los planes locales de inserción por lo económico.

* Integración profesional en los campos de la construcción y de la adecuación urbana.

* La reconversión en el medio rural.

* Acompañamiento social en un dispositivo de inserción socio-profesional.

* Las empresas contra la exclusión.

Durante 1996 se ha trabajado en una reflexión general sobre la observación de las poblaciones desfavorecidas en el marco de la inserción económica y social. Observación que es necesaria para diagnosticar mejor las necesidades de los grupos desfavorecidos, así como para programar nuevos dispositivos de acción y evaluar las acciones en curso.

Dicha reflexión general se ha concretado en cuatro seminarios que se han celebrado durante 1996.

* Observación y evaluación de poblaciones desfavorecidas.

* Observación de los recorridos individuales de inserción sociolaboral.

* Inserción sociolaboral y desarrollo local.

* La noción de "ensamblaje" en el marco de los proyectos de inserción sociolaboral para colectivos desfavorecidos

\section{Seminario celebrado en Huelva los días 12, 13 y 14 de diciembre. Noción de ensamblaje.}

El seminario "La noción de ensamblaje" celebrado en Huelva los días 12, 13 y 14 de diciembre de 1996, correspondió a la reunión de cierre del año de trabajo de la red. Este 
encuentro estableció las conclusiones del trabajo realizado en las distintas reuniones celebradas durante 1996 y marcó tas directrices de actuación de la red en el futuro.

En este seminario participaron los proyectos siguientes:

Alemania: Un proyecto de Bemburg sobre inserción sociolaboral y autoempleo de colectivos con fuerte cualificación pero provenientes de la Antigua Alemania del Este.

Bélgica: La Mission Régionale pour l'insertion et l'emploi (MIREC) de Charleroi. Puestas en marcha de proyectos locales de inserción para el empleo en una ciudad industrial con una fuerte crisis en la actualidad.

Francia: De este país participaron diferentes proyectos de las zonas de Auxerre, Besancon, Clamecy, Lille, Octeville, Paris, Perigueux. Todos estos proyectos trabajan en la información, acompañamiento e inserción socioprofesional de colectivos con dificultades en el acceso al empleo tanto en el campo urbano como rural.

Irlanda: Ha participado el proyecto "Alliance for work forum" de Dublin que también trabaja en la inserción de colectivos desfavorecidos.

Portugal: Participa la Dirección General de Acción Social como coordinadora de múltiples proyectos de inserción sociolaboral, así como el proyecto rumo novo de Vila Formoso, que trabaja más concretamente en desarrollo local como elemento de inserción sociolaboral de un territorio específico.

España: En la actualidad participan tres proyectos concretos: en Girona, está participando el ayuntamiento de esta ciudad con sus actuaciones concretas de desarrollo local. La Comisión Catolica de Ayuda al refugiado en Madrid, está trabajando en la actualidad en actuaciones concretos de inserción sociolaboral de los colectivos especificos de refugiados en distintas comunidades del Estado español. Y en Huelva está participando el proyecto “ Huelva en acción" del programa Urban.

Además, y aprovechando, que este seminario se celebraba en Huelva, se invitó a participar en sus trabajos de grupos a proyectos concretos de la provincia de Huelva que estaban trabajando en la misma problemática.

El eje temático común que se propuso a los integrantes de este seminario fue "la noción de ensamblaje". Noción que ya se venía trabajando en distintos encuentros de la red y que planteaba serias reflexiones en torno a las políticas de inserción en el seno de los diferentes países que participan en la red. Los últimos seminarios de la red tuvieron por objeti- 
vo el definir la función de ensamblaje partiendo de casos concretos en torno a la noción de ensamblaje de recorridos de inserción socio profesional.

A las dificultades de definir esta noción se añadía una cierta ambigüedad. A menudo se ha identificado la noción de ensamblaje a una función política; en otros momentos, ésta se ha identificado a la noción de partenariado y por tanto a la capacidad de movilización partiendo de una noción de territorio más exhaustiva y más general.

Los grupos de trabajo se centraron en trabajar sobre esta noción partiendo de diez principios esenciales para poder analizar éste desde contextos diferentes pero con el objetivo de elaborar instrumentos que pudiesen aglutinar intervenciones conjuntas en el campo de la inserción sociolaboral.

Los principios fueron los siguientes:

1. El concepto de territorialidad

2. El campo de acción determinado

3. La implicación de los polos institucionales

4. La legitimidad y el reconocimiento de la noción de ensamblaje

5. La plusvalía en relación a una amplia movilización de actores tanto del campo económico como social

6. La apropiación de esta noción por los diferentes actores

7. La función de movilización

8. La adaptación en distintos contextos

9. La autonomía

10. El lugar de experimentación e innovación

Además, y dado que la gran mayoría de las estructuras participantes en el seminario desarrollan su labor en el ámbito local, la cuestión de fondo sobre la que se basaron las discusiones ha sido la importancia de la dimensión local como elemento clave en materia de empleo, y la implantación de la movilización en relación a éste.

\section{Aportación del Observatorio Local de empleo como estructura de investigación estrátegica}

El Observatorio Local de empleo como instrumento de información estrátegica permite un conocimiento más exhaustivo de los diferentes actores que actúan en el amplio 
campo económico y social sobre la inserción sociolaboral de numerosos colectivos con dificultades crecientes en el accèso al empleo.

Y es ahí, desde nuestro punto de vista. donde radica nuestro papel en la red. El aprehender mejor el concepto de ensamblaje en las diferentes formas de intervención para la inserción socioprofesional de todos los colectivos que se incorporan al mercado de trabajo, y más especificamente para los colectivos con mayores dificultades. Y todo ello en un contexto donde la noción de parado está estallando y donde se están desarrollando cambios importantes en el seno de los mercados de trabajo.

El análisis del juego de los actores, la confrontación de sus proyectos, el examen de sus relaciones de fuerza nos permite analizar los desafíos estratégicos y las cuestiones claves para el futuro de los mercados de trabajo en los contextos actuales de creciente segmentación, así como del aumento de vulnerabilidad y fragilización de amplios colectivos. 